\title{
Influence of Women's Childbearing on Their Labor Productivity
}

\author{
Xuhang Zhao ${ }^{1}$ \\ ${ }^{1}$ School of Economics, Wuhan University, Wuhan, Hubei 430072, China \\ "Corresponding author. Email: 2017301120016@whu.edu.cn
}

\begin{abstract}
This paper uses the data of China Family Panel Studies (CFPS), making a distinction between urban and rural samples and analysing the impact of women's childbearing on their labour productivity. The results show that childbearing can significantly reduce women's labour productivity and marginal effects have a decreasing trend. In addition, the higher a woman's education, the less impact it has. Furthermore, rural women are more likely to be discriminated against in the labour market, while the effect of urban women's childbearing on their labour productivity is more significant.
\end{abstract}

Keywords: labour productivity, discrimination on birth, number of children

\section{INTRODUCTION}

With the transformation and upgrading of China's economy, China's population structure is also undergoing tremendous changes. According to the China Fertility report, one of the main characteristics of China's population is the continuous decline in fertility. Since the introduction to the population policy in 1970, China's fertility rate is an average of six children per woman. By 1980, it had declined to about two children, and now it has averaged less than one child per woman. The decline of fertility rate will have a huge and far-reaching impact on China's economic structure, population scale, labor market supply and other aspects, including the impact of female fertility on its labor productivity. The impact of childbearing on female labor productivity has always been a hot topic in the field of labor economics. Women's decision-making between childbearing and work will change the structure of China's labor market greatly, thus changing the structure of women's wages. In the process of selection, it is often decided by income effect and substitution effect. In the context of the continuous decline in fertility, more women will take the initiative to enter the labor market to improve personal labor productivity in a competitive environment, but at the same time, women who choose to have children will, on the one hand, distribute productivity in their families and work, on the other hand, they can be discriminated by the labor market reducing personal labor productivity. In addition, due to the significant differences between urban and rural areas, the differences between urban and rural women will affect the accuracy of the results.

To solve this problem, this paper uses CFPS data to test the impact of the number of children on the labor supply behavior and wage level of women in urban and rural samples, and uses Heckman two-step model to solve the deviation in sample selection. Using Oaxaca blinder decomposition method to prove that the decrease of female labor productivity is not mainly due to the difference of productivity level compared with men, but also due to the discrimination effect of labor market on female fertility, which provides a new theoretical basis for this subject.

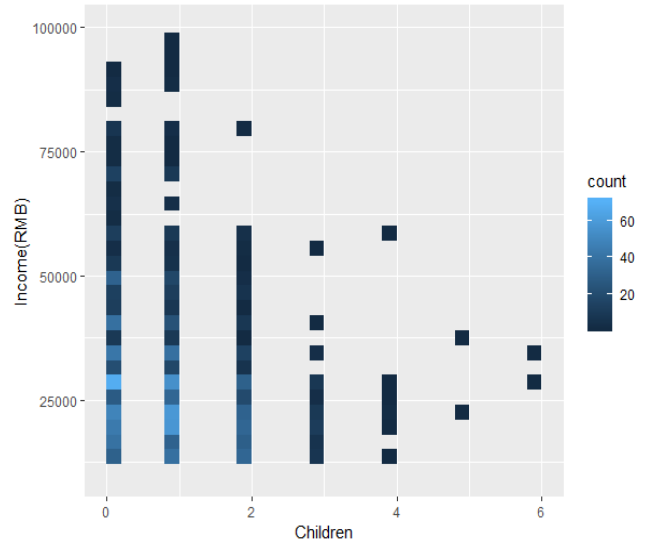

Figure 1. The Relationship between Female Income and the Number of Children

\section{BACKGROUND}

The substitution effect is that women allocate more time and energy to the family sector, that is, women are more inclined to invest in family human capital. According to the research of Mincer (1962), this kind of family's human capital investment will replace market activities more than leisure [1]. In addition, with the improvement of living standards, the rising price of children's education and the rising cost of nursing will enlarge this substitution effect. When such costs gradually increase to greater than the opportunity cost of giving up work, "rational" women will give up work and spend all their time in family production, which is reflected in the substitution effect. Gronau (1977) research results show that men are mainly engaged in market labor, so the increase of family population burden has a more significant 
impact on women's labor participation, which is reflected in the income effect [2]. Specifically, in order to make up for the loss caused by childbirth, the increase of employment motivation leads to the increase of labor participation rate and labor productivity.

Becker et al. (1960) analyzed the impact of women's childbearing on their income. They believed that rational decision-making families would take the maximization of utility as their goal. Therefore, because high-income families pay more attention to the quality of their children than the number of their children, there will be an inverted U-shaped relationship between their income and the number of their children [3]. When the income increases to a certain range, women will prefer to have fewer children, and there is an alternative relationship between the quality and quantity of children. Polachek (1980) believed that the impact of the number of children on women's income also needs to consider women's occupational attributes [4]. Women engaged in formal employment have higher cost and lower willingness to bear, and women are more strongly constrained by income. On the other hand, women who are engaged in physical work with relatively low technical content have more negative impact on their income when they are interrupted due to their income.

In addition, there is widespread discrimination among women in the labor market. Aigner and Cain (1977) first introduced this mechanism into an incomplete information model, and provided a standard analysis framework for the existence of discrimination, which was used to explain wage discrimination and promotion discrimination [5]. Langand manove (2011) proposed that the discriminated groups whose productivity is more difficult to calculate are more motivated to invest in the education level, which means that the discriminated groups (i.e. women with childbearing history) tend to have lower wages under the same education level [6]. Arrow (1971), a rational stereotype, put forward that enterprises think that workers of discriminated groups are less likely to have higher labor productivity [7]. This stereotype will make women's expectations of labor productivity decline after childbirth, which to some extent hinders women's promotion and reduces their potential productivity.

Women's childbearing is also affected by many factors. In China, due to the influence of traditional concepts, there is a regional effect on female fertility rate, as shown in Figure 2. For example, in Shandong, Tibet and other regions, the fertility rate of women exceeds the national average, while in the three eastern provinces, the fertility rate is very low. According to Chuanchuan Zhang's (2011) study, it is suggested that in the study of the relationship between female fertility rate and labor productivity, we should control the provincial dummy variables to reach a more realistic conclusion [8]. Based on the analysis of UHS (micro data of China urban household survey), Lu Lili (2014) found that the negative impact of children on female labor participation rate is increasing, and the impact of education level, whether they live with their parents or not, and the wage gap of their spouses are weakening on the overall level [9]. Xiaoyuan Dong and Fenglian Du (2010) reached similar conclusions based on CHNS (China Nutrition and health survey data) from 1991 to 2004 [10].

\section{DATA DESCRIPTION}

The data used in this paper are from CFPS. CFPS is initiated by the China Social Science Research Center of Peking University. It reflects the changes of China's society, economy, population, education and health by tracking and collecting the amount data of individuals, families and communities. CFPS focuses on the economic and noneconomic welfare of Chinese residents, including economic activities, educational achievements, family relations and family dynamics, population migration, health and many other research topics. It is a national, large-scale, multidisciplinary social tracking survey project. The sample covers 25 provinces / cities / autonomous regions, and the sample size is 16000 households. The respondents include all family members in the sample families. At present, CFPS has published some data of 2012, 2014, 2016 and 2018, and selected sample data of 2014, 2016 and 2018 in combination with the research topic of this paper. In the three-year sample data, all the women with childbearing history are selected as the samples, focusing on the analysis of the impact of the number of children born by women on their labor productivity, and the women's education level, age, residence, urban and rural household registration, weekly working hours, nature of employers and their industries are selected as other control variables.

The analysis of this paper is based on all the female samples with reproductive history in the samples surveyed by CFPS. After further eliminating the sample points with incomplete information and missing key variables, there are 9127 urban samples and 4388 rural samples left. Descriptive statistics for all samples are given in Table 1. Due to the differences in work form and life concept between urban and rural residents, there will be great differences in the impact of women's childbearing on labor productivity. Therefore, in the analysis process of this paper, the urban and rural samples will be regression analysis respectively, and get more realistic statistical conclusions. In the urban sample, the average age of women was 37.758 years old, slightly higher than 34.275 years old in the rural sample. In the sample with wage income, the average woman in the urban sample works 4.743 hours less per week than the rural women, but the average annual income is 8342 yuan more than the rural women. In the whole sample, women in urban sample have 0.985 children on average, and women in rural sample have 1.139 children on average. In the urban sample, women's education level is generally concentrated in junior high school and above, while in the rural sample, women's education level is generally concentrated in primary school and junior high school. The trend of education level in the sample with wage income is the same as that in the whole sample. reached similar conclusions based on CHNS (China Nutrition and health survey data) from 1991 to 2004 [10]. 
Table 1 Descriptive statistics of variables

\begin{tabular}{|c|c|c|c|c|}
\hline \multirow{2}{*}{ Variable } & \multicolumn{2}{|c|}{ Full Sample } & \multicolumn{2}{|c|}{ Sample with income } \\
\hline & Urban Sample & Rural Sample & Urban Sample & Rural Sample \\
\hline \multirow[t]{2}{*}{ Urban/Rural } & 1 & 0 & 1 & 0 \\
\hline & $(0)$ & $(0)$ & (0) & $(0)$ \\
\hline \multirow[t]{2}{*}{ Education_level } & 3.442 & 2.654 & 3.406 & 2.694 \\
\hline & $(1.971)$ & $(1.835)$ & $(2.078)$ & (1.904) \\
\hline \multirow[t]{2}{*}{ Age } & 37.758 & 34.275 & 36.813 & 33.987 \\
\hline & $(11.45)$ & (11.748) & (11.17) & $(11.581)$ \\
\hline \multirow[t]{2}{*}{ WH_pw } & 32.504 & 38.215 & 48.036 & 52.779 \\
\hline & $(28.754)$ & $(30.813)$ & $(16.53)$ & (19.111) \\
\hline \multirow[t]{2}{*}{ Income } & 21606.97 & 16458.72 & 30850.45 & 22508.31 \\
\hline & $(384.66)$ & $(181.35)$ & $(366.6)$ & $(504.47)$ \\
\hline \multirow[t]{2}{*}{ Children } & 0.985 & 1.139 & 0.968 & 1.146 \\
\hline & $(0.878)$ & $(1.05)$ & $(0.91)$ & (1.084) \\
\hline \multirow[t]{2}{*}{ LogWage } & 1.607 & 1.398 & 2.294 & 1.912 \\
\hline & $(1.355)$ & (1.209) & $(1.022)$ & (1.009) \\
\hline \multirow[t]{2}{*}{ College_Above } & 0.038 & 0.012 & 0.048 & 0.015 \\
\hline & $(0.19)$ & $(0.11)$ & $(0.213)$ & $(0.12)$ \\
\hline \multirow[t]{2}{*}{ Highschool } & 0.269 & 0.121 & 0.27 & 0.131 \\
\hline & $(0.444)$ & $(0.326)$ & $(0.444)$ & $(0.337)$ \\
\hline \multirow[t]{2}{*}{ JuniorHigh } & 0.226 & 0.194 & 0.219 & 0.207 \\
\hline & $(0.418)$ & $(0.396)$ & $(0.413)$ & $(0.405)$ \\
\hline \multirow[t]{2}{*}{ Elementary_below } & 0.467 & 0.672 & 0.464 & 0.648 \\
\hline & $(0.499)$ & $(0.47)$ & $(0.499)$ & $(0.478)$ \\
\hline Obs & 9127 & 4388 & 6393 & 3209 \\
\hline
\end{tabular}

Note: standard deviation is in brackets. The education variable is a binary variable. For example, if the education level is high school / secondary school / junior college, the variable is assigned as 1 , otherwise it is assigned as 0 , and the control group is "no schooling".

Through further analysis of the sample data, we can see that women's childbearing has a significant impact on their wage level. The results show that every child a woman has will reduce her corresponding wage income, and the negative effect of this kind of child-bearing is in a marginal decreasing trend. That is to say, giving birth to the first child has the greatest impact on women's income, and then the impact of every extra child on women's income gradually decreases. Compared with the average hourly wage of nonchildbearing women, giving birth to the first child will reduce the hourly wage of women by $22 \%$, and giving birth to two children will reduce the female income by $25 \%$. Comparing the women with different education level and their fertility intention, we can find that the education level of women has little influence on their fertility intention. According to the data analysis of the whole sample, the influence of women's education level on the number of births is not significant within the range of normal number of births. However, among the super born and multi born groups, women with lower education level account for the vast majority.

\section{RESEARCH METHOD}

According to the analysis of the relationship between labor productivity and wage level by Lichun $\mathrm{Li}$ and $\mathrm{Li}$ Dong (2008), the ratio of wage increase and labor productivity in China has fluctuated around a small range since 1985, which shows that the fluctuation of wage increase and decrease and labor productivity in recent 20 years is matched [11]. Therefore, this paper uses the logarithm of the unit hourly wage to quantitatively express the labor productivity of women in China. The main regression variable is the number of children born by women. The control variables include age, age square, education level, as well as the nature of provinces and cities, employers, and virtual variables of their industries.

There is a serious problem of self-selection in the study of the impact of childbearing on wage level. When we assume that wage income is related to education, age and other factors, only when women choose to work can we observe their wage income. If women decide whether to work at random, there is no longer a question of sample selection. 
But in fact, the decision whether to work or not is not random, but influenced by many factors. For example, women decide to work only if the wage offered by the employer is higher than the "reserved wage" offered by women. Therefore, if only through the regression analysis of the existing data, the results must be selective biased, because we only consider the part of women who participate in the work, and can not get the impact of childbearing on their labor productivity for all women.

When there is a sample selection problem, the usual method is to use Heckman two-step regression. The main principle of this method is: first, estimate the probability (possibility) of women with different number of children participating in the work, which can be obtained through empirical data model. The statistical estimation results can be used to predict the probability of each individual. Next, we combine these predicted individual probabilities into an additional explanatory variable, and correct the sub selection problem together with education, age and other variables. In this way, the regression model is very appropriate in the statistical sense. The specific measurement model is as follows:

$\operatorname{lhw}_{i}=\beta_{0}+\beta_{1}$ childn $_{1 i}+\sum \gamma_{i j} X_{i j}+\varepsilon_{1 i}$

(1)

$$
\beta_{1}{ }^{\prime} \operatorname{childn} 2_{i}+\sum \gamma_{i j}{ }^{\prime} X_{i j}{ }^{\prime}+\varepsilon_{2 i}
$$

$$
\boldsymbol{e}_{\boldsymbol{i}}=\boldsymbol{\beta}_{0}{ }^{\prime}+
$$

Equation (1) is the logarithm hourly wage equation, $\boldsymbol{l h} \boldsymbol{w}_{\boldsymbol{i}}$ is the logarithm of unit hourly wage of the ith observation value, and $\boldsymbol{c h i l d n _ { i }}$ is the number of children, which are the key variables in this paper. $\boldsymbol{X}_{\boldsymbol{i} \boldsymbol{j}}$ are control variables, including age, age square, education level, working hours per week, as well as the nature of employers, the industry and the virtual variables of provinces and cities. $\boldsymbol{\varepsilon}_{\boldsymbol{i}}$ is the random error term. Equation (2) is the working tendency equation, in which $\boldsymbol{E}\left(\boldsymbol{\varepsilon}_{1}\right)=\mathbf{0}, \boldsymbol{E}\left(\boldsymbol{\varepsilon}_{2}\right)=\mathbf{0}, \boldsymbol{\varepsilon}_{\mathbf{1}}$ and $\boldsymbol{\varepsilon}_{\mathbf{2}}$ are positively correlated. General estimation (1) will get the estimator with selective bias. According to the two-step correction method proposed by Heckman (1979), the regression model is finally obtained as follows:

lhw $w_{i}=\beta_{0}+\beta_{1}$ childn $_{i}+\sum \gamma_{i j} X_{i j}+\rho \sigma_{1} \lambda_{i}+\varepsilon_{i}$

Where $\rho$ is the correlation coefficient of $\varepsilon_{1}$ and $\varepsilon_{2}$. And $\sigma_{1}$ is the standard deviation of $\varepsilon_{1} . \lambda_{i}=$ $\frac{\emptyset\left(\beta_{1^{\prime}} \text { childn } 2_{i} / \sigma_{2}\right)}{\Phi\left(\beta_{1^{\prime}} \text { childn } 2_{i} / \sigma_{2}\right)}, \sigma_{2}$ is the standard deviation of $\varepsilon_{2}$.

In the specific operation process, firstly, according to probit model, we estimate the work tendency equation, calculate $\lambda_{i}$ using all samples (including women who do not participate in the labor market), and then use the selective samples, take $\rho \sigma_{\mathbf{1}}$ as an estimation parameter, estimate the model (3), and get the estimation of the number of children $\widehat{\boldsymbol{\beta}_{1}}$.

It is not enough to say that there is sexism and procreation discrimination in the labor market. There are many reasons for this phenomenon, either because of the decrease of labor productivity due to the birth of women, or because of the different productive conditions of men and women due to the birth of women. For example, when the education level of women is very low, the gap of labor productivity caused by childbirth may reflect the gap of education level. Therefore, if we want to continue to explore whether there is a real phenomenon brought about by women's childbearing in the labor market, we need to construct a "woman regarded as a male", that is, the control group that can't bear. By comparing the income levels of the two groups of samples, we can get further conclusions. The main operations are as follows:

$\ln Y^{M}=X_{M} \beta_{M}$

$\ln Y^{F}=X_{F} \beta_{F}$

$\ln Y^{C}=X_{F} \beta_{M}$

Among them, women's income is recorded as $\boldsymbol{Y}^{\boldsymbol{M}}$, men's income is recorded as $\boldsymbol{Y}^{\boldsymbol{F}}, \boldsymbol{Y}^{\boldsymbol{M}}$ and $\boldsymbol{Y}^{\boldsymbol{F}}$ are factors related to men's and women's productivity conditions, such as the number of children, education level, age, etc. $\boldsymbol{\beta}_{\boldsymbol{M}}$ and $\boldsymbol{\beta}_{\boldsymbol{F}}$ represent the wage return coefficient of men and women in

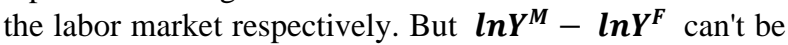
directly expressed as the difference between them. We need to build a group of women who are regarded as "men", whose income is recorded as $\boldsymbol{Y}^{\boldsymbol{C}}$. From equation (4) - (5), we can get:

$$
\ln Y^{M}-\ln Y^{F}=\beta_{M}\left(X_{M}-X_{F}\right)+\left(\beta_{M}-\beta_{F}\right) X_{F}
$$

In which the "explainable part", i.e. the difference of labor productivity caused by the different conditions of productivity, can be expressed as: $\boldsymbol{\beta}_{\boldsymbol{M}}\left(\boldsymbol{X}_{\boldsymbol{M}}-\boldsymbol{X}_{\boldsymbol{F}}\right)$; "unexplainable part", i.e. the difference of labor productivity caused by the different return coefficients of men and women can be expressed as: $\left(\boldsymbol{\beta}_{\boldsymbol{M}}-\boldsymbol{\beta}_{\boldsymbol{F}}\right) \boldsymbol{X}_{\boldsymbol{F}}$. The "unexplainable part" can be understood as the discriminatory factors brought about by the failure of men to have children due to the birth of women.

\section{REGRESSION ANALYSIS}

\subsection{Two-step of Heckman}

Firstly, the influence of the number of children born by women on whether women enter the labor market is investigated. As the interpreted variable is a binary discrete variable, it is compared with the regression results of probit model on the basis of OLS regression, and the results are given in Table 2. The regression results show that the increase of the number of female children in both urban and rural areas will significantly reduce the probability of women entering the labor market. Taking OLS regression results as an example, for rural women, having one more child will significantly reduce the probability of entering the labor market by 5 percentage points; for urban women, having one more child will significantly reduce the probability of entering the labor market by 8.8 percentage points, and the impact of the number of children on entering the labor market is statistically significant at the level of $1 \%$. According to the regression results of women's age and age square, we can see that the probability of women entering the labor market increases first and then decreases with the increase of age, but compared with urban women, the probability of rural women entering the labor market is more susceptible to the influence of age factors. According to the regression results, the higher the education level of women, the more likely they are to enter the labor market. 
high school and university education, urban women are more likely to enter the labor market than rural women. The coefficients of other control variables basically meet our

expectations.
As the education level of women in rural groups is generally low, in junior high school and primary school and below, women in rural samples are more likely to enter the labor market than urban women. Among the sample women with

Table 2 The Influence of the Number of Children on Entering the Labor Market

\begin{tabular}{ccccc}
\hline \multirow{2}{*}{ Variable } & \multicolumn{2}{c}{ OLS } & \multicolumn{2}{c}{ Probit } \\
\cline { 2 - 5 } Children & Urban Sample & Rural Sample & Urban Sample & Rural Sample \\
& $-0.088^{* * *}$ & $-0.051^{* * *}$ & $-0.041^{*}$ & $-0.030^{* *}$ \\
WH_pw & $(0.014)$ & $(0.017)$ & $(0.023)$ & $(0.027)$ \\
& $0.025^{* * *}$ & $0.017^{* * *}$ & $0.047^{* * *}$ & $0.037^{* * *}$ \\
Age & $(0.01)$ & $(0.001)$ & $(0.01)$ & $(0.001)$ \\
& $0.058^{* * *}$ & $0.052^{* * *}$ & $0.057^{* * *}$ & $0.052^{* * *}$ \\
Age_square & $(0.007)$ & $(0.009)$ & $(0.01)$ & $(0.013)$ \\
& $-0.001^{* * *}$ & $-0.018^{*}$ & $-0.001^{* * *}$ & $-0.098^{* * *}$ \\
College_above & $(0.018)$ & $(0.011)$ & $(0.062)$ & $(0.048)$ \\
& $1.326^{* * *}$ & $0.742^{* * *}$ & $0.876^{* * *}$ & $-0.001^{* * *}$ \\
Highschool & $(0.062)$ & $(0.147)$ & $(0.122)$ & $(0.151)$ \\
& $0.576^{* * *}$ & $0.63^{* * *}$ & $0.384^{* * *}$ & $0.306^{* * *}$ \\
JuniorHigh & $(0.028)$ & $(0.051)$ & $(0.046)$ & $(0.226)$ \\
& $0.103^{* * *}$ & $0.223^{* * *}$ & $0.091 *$ & $0.472^{* * *}$ \\
Elementary_below & $(0.03)$ & $(0.042)$ & $(0.048)$ & $(0.081)$ \\
& $0.117^{*}$ & $0.053^{* * *}$ & 0.340 & $0.243^{* * *}$ \\
Constant & $(0.067)$ & $(0.018)$ & $(0.216)$ & $(0.065)$ \\
& $-0.411^{* * *}$ & $-0.202^{* * *}$ & $-2.107^{* * *}$ & $-0.008^{* * *}$ \\
Obs & $(0.125)$ & $(0.154)$ & $(0.196)$ & $(0.027)$ \\
R ${ }^{2}$ & 9127 & 4388 & 9127 & 4388 \\
& 0.343 & 0.224 & & \\
\hline
\end{tabular}

Note: standard error in brackets. ${ }^{* * *} \mathrm{p}<0.01,{ }^{* *} \mathrm{p}<0.05,{ }^{*} \mathrm{p}<0.1$. The control group of education level was "no schooling".

According to the above, the number of children will have an impact on women's decision whether to enter the labor market or not, and also on their labor productivity, which is expressed by the logarithm of women's hourly wage. For some married women, there are many children who still participate in employment, but the investment in working hours and energy distribution will still affect their labor productivity, which is reflected in the change of wage level. Therefore, the next step is to further analyze the impact of women's fertility on their labor productivity, specifically using Heckman two-step regression, and the empirical model is shown in equation (3). Table 3 shows the regression results with the dependent variable being the logarithm of hourly wage.

From the results reported by the inverse millsby in Table 3 (i.e. the original hypothesis of sample selection coefficient in Heckman's two-step estimation, i.e. the test result of $h_{-}$: $\rho=0$ ), it can be seen that the inverse millsby is significant at the significance level of $1 \%$, i.e. there is sample selection problem, so the Heckman two-step regression method needs to be used. The estimation results of the income equation of the overall sample show that the increase of the number of children will significantly reduce women's income, which is applicable to both urban and rural samples, and for urban women, the negative effect of the decrease of income brought by each additional child is greater than that of rural women. In terms of age, the wage level of women increases with the increase of age, and the education level has a significant impact on women's income. The higher the education level of women, the higher their labor productivity will also increase. Compared with women with high education level, low education level will reduce women's income in general, which is more obvious in the urban sample. 
Table 3 The Influence of the Number of Children on the Logarithm of Hourly Wage

\begin{tabular}{cccc}
\hline & Full Sample & Urban Sample & Rural Sample \\
\hline Children & $-0.086^{* * *}$ & $-0.086^{* * *}$ & $-0.067^{* * *}$ \\
WH_pw & $(0.009)$ & $(0.012)$ & $(0.015)$ \\
& $0.01 * * *$ & $-0.012^{* * *}$ & $-0.006^{* * *}$ \\
Age & $(0.001)$ & $(0.001)$ & $(0.002)$ \\
& $0.096^{* * *}$ & $0.094^{* * *}$ & $0.087 * *$ \\
Age_square & $(0.005)$ & $(0.006)$ & $(0.008)$ \\
& $-0.001^{* * *}$ & $-0.001^{* * *}$ & $-0.001^{* * *}$ \\
College_above & $(0.034)$ & $(0.053)$ & $(0.035)$ \\
& $0.941^{* * *}$ & $0.642^{* * *}$ & $0.546^{* * *}$ \\
Highschool & $(0.048)$ & $(0.126)$ & $(0.033)$ \\
& $0.414^{* * *}$ & $-0.538^{* * *}$ & $-0.32^{* *}$ \\
JuniorHigh & $(0.026)$ & $(0.049)$ & $(0.126)$ \\
& $0.326^{* * *}$ & $-0.929 * * *$ & $-0.715^{* * *}$ \\
Elementary_below & $(0.035)$ & $(0.053)$ & $(0.125)$ \\
& $-0.129^{* * *}$ & $-1.043 * * *$ & $-0.852^{* * *}$ \\
mills & $(0.021)$ & $(0.053)$ & $(0.123)$ \\
lambda & $0.937^{* * *}$ & $0.849^{* * *}$ & $1.11^{* * *}$ \\
Constant & $(0.074)$ & $(0.097)$ & $(0.113)$ \\
& $0.866^{* * *}$ & $2.013 * * *$ & $1.397 * * *$ \\
Obs & $(0.13)$ & $(0.163)$ & $(0.222)$ \\
& 9112 & 6123 & 2989 \\
\hline
\end{tabular}

Note: standard error in brackets. ${ }^{* * *} \mathrm{p}<0.01,{ }^{* *} \mathrm{p}<0.05,{ }^{*} \mathrm{p}<0.1$. The control group of education level was "no schooling".

\subsection{Oaxaca - blinder Decomposition}

Oaxaca blinder decomposition was used to analyze the difference of labor productivity of women's childbearing, and men were the reference group and women were the control group. Among them, the education level is divided according to different educational background: illiteracy is 0 , primary school is 3 , junior high school is 4 and so on. The decomposition results are shown in Table 4. From the decomposition results, we can see that the average logarithmic hourly wage of men is 2.385 , the average logarithmic hourly wage of women is 2.087 , the difference between the two is 0.298 , the income level of men is $14.28 \%$ higher than that of women, and the income gap between men and women is more significant in rural samples. For this difference, the interpretable part is -0.021 and the unexplainable part is 0.319 . It shows that from the sample data, the income gap between men and women due to different productivity conditions is small, and most of the differences are reflected in the "unexplained part" In the "unexplainable part", the comparison objects are all women. The difference is the perspective of the labor market on women. It can not be explained by the real differences in labor conditions between men and women. It can be understood as the income gap caused by the birth of women and the non-birth of men in the labor market, which indicates that there is discrimination in the labor market. In the "explainable part" of the income gap caused by different objective labor conditions of men and women, the difference caused by the number of children only accounts for $9.5 \%$, the influence factor caused by age accounts for $30 \%$, and the education level accounts for $60 \%$. It shows that under the objective conditions, the number of children should not be regarded as a key criterion to affect the income level, and the internal factors such as education level can play a more decisive role. And by comparing the urban sample and the rural sample, we can find that compared with the rural sample, the urban pays more attention to the education level of women. In addition, the proportion of children in the "unexplained part" of the labor market has increased. The difference caused by the number of children accounts for $15.2 \%$, including $14.78 \%$ in the urban sample and $21.7 \%$ in the rural sample. This shows that the impact of women's childbearing on labor productivity in the rural sample is more serious than that in the urban sample. Through the analysis of the results in the table, it can be seen that there is discrimination against women's childbearing in both urban and rural areas. However, because the decomposition only involves the key variables such as gender, number of children, age and 
reducing the labor-bearing rate of women, but it can not be explained that women's childbearing is the cause of productivity reduction. education level, and does not list all factors that may affect the wage level, it can only be inferred that women's childbearing will be discriminated by the labor market, thus

Table 4 Oaxaca-Blinder Decomposition Result

\begin{tabular}{|c|c|c|c|}
\hline Ln_wage & Full Sample & Urban Sample & Rural Sample \\
\hline \multicolumn{4}{|l|}{ Total } \\
\hline \multirow[t]{2}{*}{ Male } & 2.385 & 2.526 & 2.185 \\
\hline & $(0.009)$ & $(0.012)$ & $(0.014)$ \\
\hline \multirow[t]{2}{*}{ Female } & 2.087 & 2.234 & 1.815 \\
\hline & $(0.012)$ & $(0.014)$ & $(0.02)$ \\
\hline \multirow[t]{2}{*}{ Difference } & 0.298 & 0.292 & 0.37 \\
\hline & $(0.015)$ & $(0.019)$ & $(0.024)$ \\
\hline \multirow[t]{2}{*}{ Explainable part } & -0.021 & -0.021 & -0.011 \\
\hline & $(0.005)$ & $(0.007)$ & $(0.007)$ \\
\hline \multirow[t]{2}{*}{ Unexplainable part } & 0.319 & 0.313 & 0.381 \\
\hline & $(0.015)$ & $(0.018)$ & $(0.025)$ \\
\hline \multicolumn{4}{|l|}{ Explainable part } \\
\hline \multirow[t]{2}{*}{ Children } & -0.002 & 0.001 & -0.001 \\
\hline & $(0.001)$ & $(0.001)$ & $(0.001)$ \\
\hline \multirow[t]{2}{*}{ Age } & 0.009 & 0.006 & -0.004 \\
\hline & $(0.003)$ & $(0.003)$ & $(0.006)$ \\
\hline \multirow[t]{2}{*}{ Education } & -0.028 & -0.027 & -0.005 \\
\hline & $(0.005)$ & $(0.006)$ & $(0.004)$ \\
\hline \multicolumn{4}{|l|}{ Unexplainable part } \\
\hline \multirow[t]{2}{*}{ Children } & 0.079 & 0.072 & 0.094 \\
\hline & $(0.018)$ & $(0.022)$ & $(0.03)$ \\
\hline \multirow[t]{2}{*}{ Age } & -0.078 & -0.027 & -0.03 \\
\hline & $(0.048)$ & $(0.063)$ & $(0.08)$ \\
\hline \multirow[t]{2}{*}{ Education } & -0.122 & -0.174 & -0.021 \\
\hline & $(0.029)$ & $(0.04)$ & $(0.043)$ \\
\hline \multirow[t]{2}{*}{ Constant } & 0.44 & 0.441 & 0.337 \\
\hline & $(0.058)$ & $(0.079)$ & $(0.091)$ \\
\hline Obs. & 22168 & 13232 & 8471 \\
\hline
\end{tabular}

Note: the standard error of robustness is shown in brackets. The male sample is the reference group and the female sample is the control group.

\section{CONCLUSION}

On the one hand, women's childbearing will affect women's motivation to enter the labor market, reduce women's labor participation rate, on the other hand, it will significantly reduce women's labor productivity. Based on the data of CFPS, this paper discusses the impact of women's childbearing on their labor productivity, and compares the differences between urban and rural areas on women's labor productivity through the analysis of urban and rural areas. Heckman's two-step method was used to eliminate the serious sample selection problem in this kind of problem. Through Oaxaca blind decomposition method, the internal cause of female labor productivity was further explored as the difference in female fertility or production conditions. Based on this analysis, the reasons for the decline in female labor productivity are derived.. This paper holds that: 1 .Women's childbearing will significantly reduce women's labor productivity. Through the analysis of the regression results, we can see that there is a significant negative effect between the number of children born by women and their wage level. And this negative effect has a trend of diminishing marginal effect, that is, the effect of each extra child on the female wage level is gradually reduced. Having three or more children has no significant effect on the wage level.

2.Compared with the rural samples, the impact of childbearing on labor productivity of urban women is greater, that is, the higher the opportunity cost of having more children for urban women. In addition, more attention is paid to the education level of women in urban samples. The higher the education level of women is, the more likely they are to enter the labor market. However, this phenomenon is not significant in rural samples.

3.The labor productivity and age of women show an inverted U-shaped change. With the increase of women's age, women's labor and production first increased and then decreased. In the urban sample, the effect of decreasing female labor productivity is not significant with the increase of age, while in the rural sample, when the age increases to a certain extent, the female labor productivity will decline significantly.

4. Under the same conditions, the decline of women's productivity is partly due to the discrimination effect of the labor market on women, and only a small part of the 
difference in wage level is caused by the different levels of productivity. In terms of productivity, the labor market pays more attention to the education level of women, while the number of children born by women and the proportion of age factors have increased in the discrimination effect.

5 . Women can reduce the wage difference caused by birth discrimination by improving their education level. The higher the education level, the smaller the impact of having children on reducing labor productivity, which is reflected in urban and rural samples, especially in urban samples.

\section{REFERENCES}

[1] Mincer J. Intercountry comparisons of labor force trends and of related developments: an overview.[J]. Journal of Labor Economics, 1985,3(1 Pt 2).

[2] Reuben Gronau. Leisure, Home Production and Work--The Theory of The Allocation of Time Revisited[J]. Journal of Political Economy, 1976, 85(6):1099-1123.

[3] Ghez G, Becker G S. A Theory of the Allocation of Time and Goods Over the Life Cycle[J]. 2009, 32(6):746.

[4] Mincer J, Polachek SW. Family investments in human capital: earnings of women.[J]. The Economics of Women \& Work, 1980, 82(2):76-76.

[5] Dennis J. Aigner and Glen G. Cain. Statistical Theories of Discrimination in Labor Markets[J]. Ilr Review, 30(2):175-187.

[6] Lang, Kevin, Manove, Michael. Education and Labor Market Discrimination[J]. American Economic Review, 101(4):1467-1496.

[7] Arrow K J. Some Models of Racial Discrimination in the Labor Market[J]. 1971.

[8] Chuanchuan Zhang. The influence of the number of children on the labor supply and wages of married women $[\mathrm{J}]$. Population and economy (5): 32-38

[9] Lili Lu. A study on the labor supply and income distribution effect of married women in urban China [D]. Zhejiang University, 2014

[10] Fenglian Du, Xiaoyuan Dong. Empirical research on women's labor participation and preschool education choice in transition period: a case study of Chinese cities and towns [J]. World economy, 2010 (2)

[11] Lichun Li, Li Dong. An analysis of the relationship between the total labor productivity and the wage level in China [J]. Economist (12): 70-71 